\title{
Brief Report: Using Individualized Orienting Cues to Facilitate First-Word Acquisition in Non-Responders with Autism
}

\author{
Robert L. Koegel · Larisa Shirotova • \\ Lynn K. Koegel
}

Published online: 2 June 2009

(c) The Author(s) 2009. This article is published with open access at Springerlink.com

\begin{abstract}
Though considerable progress has been made in developing techniques for improving the acquisition of expressive verbal communication in children with autism, research has documented that $10-25 \%$ still fail to develop speech. One possible technique that could be significant in facilitating responding for this nonverbal subgroup of children is the use of orienting cues. Using a multiple baseline design, this study examined whether individualized orienting cues could be identified, and whether their presentation would result in verbal expressive words. The results suggest that using individualized orienting cues can increase correct responding to verbal models as well as subsequent word use. Theoretical and applied implications of orienting cues as they relate to individualized programming for children with autism are discussed.
\end{abstract}

Keywords Autism · Non-responders · Orienting cue · Individualized intervention $\cdot$ Nonverbal

R. L. Koegel ( $₫) \cdot$ L. Shirotova · L. K. Koegel

Koegel Autism Center, University of California, Santa Barbara,

Phelps Hall 1150, Santa Barbara, CA 93106-9490, USA

e-mail: koegel@education.ucsb.edu

R. L. Koegel

Department of Counseling, Clinical, and School Psychology,

University of California, Santa Barbara,

Santa Barbara, CA, USA

R. L. Koegel · L. Shirotova - L. K. Koegel

The Special Education, Disability, and Risk Studies

Program in the Gevirtz Graduate School of Education,

University of California,, Santa Barbara, CA, USA

\section{Introduction}

Given that verbal communication is a positive prognostic indicator (Gillberg 1991; Howlin et al. 2000; Venter et al. 1992), the lack of communication is one of the most concerning symptoms that children with autism present. Although, follow-up studies of 2-year-olds suggest that $75-90 \%$ of children with autism acquire functional expressive communication (Eaves and Ho 2004; Charman et al. 2005; Koegel 2000; McGee et al. 1999; Turner et al. 2006), there continues to be a subgroup of children who do not (cf. Sherer and Schreibman 2005). Thus, in developing effective programming, it is imperative that all methods continually evaluate their curricula, so that the child's behavior always guides the intervention, as the population of children with autism is so heterogeneous (Sherer and Schreibman 2005; Pelios and Lund 2001) that it is almost impossible to design a one-size-fits-all approach.

One technique that might facilitate speech acquisition for this subgroup of children, who are having difficulty progressing in intervention, is the use of orienting cues. The literature suggests that the basic visual orienting processes among children with autism are intact and are similar to their peers when orienting cues are employed (Burack et al. 1997; Goldstein et al. 2001). A few studies have investigated the use of orienting cues in facilitating discrimination learning related to language. For example, Koegel et al. (1981) found that when children with autism were required to make an overt orienting response (i.e., by verbally labeling the relevant cue) during discrimination tasks, rapid acquisition occurred. Additionally, researchers have shown that, though time consuming, the use of a rapid generalized motor imitation antecedent could be used to induce vocal imitations in nonverbal children with autism (Ross and Greer 2003; Tsiouri and Greer 2003). Still, there 
remains limited research concerning individualized techniques to support non-responders with autism.

Thus, the purpose of the present study was to assess whether presenting brief individualized orienting cues, prior to presenting verbal models, would result in the production of verbal expressive words in nonverbal children with autism who had a history of non-responding.

\section{Methods}

\section{Participants}

Three children participated in this study. Each child had: (1) a diagnosis of autism by an outside agency, confirmed by our Center according to the DSM-IV-TR (American Psychiatric Association 2000); (2) no functional words and no object-label correspondence; and (3) participated in pivotal response treatment (PRT; Koegel et al. 2003; Koegel and Koegel 2006) utilizing standard intervention procedures for a minimum of 8 months. Table 1 presents information on the participants.

\section{Setting}

Parker and Alex were seen in their homes. Zane was seen at the Koegel Autism Center at the University of California, Santa Barbara.

\section{Experimental Design and Procedure}

A non-concurrent multiple-baseline across participants design was employed (Barlow and Hersen 1973). Systematically staggered baseline sessions were conducted 1 day per week for approximately $4 \mathrm{~h}$ per day for 9-28 weeks, followed by $6-10$ weeks of intervention where individualized orienting cues were presented. A manualized PRT intervention (Koegel et al. 2003) was implemented, during both baseline and intervention. The only difference between the conditions was that during intervention an individualized orienting cue was provided to evoke attention prior to presenting a verbal prompt for expressive communication.

\section{Baseline}

During baseline a standard intervention without a specific orienting cue was implemented according to the procedures described for PRT (Koegel et al. 2003; Koegel and Koegel 2006). Specifically, a trial began when the interventionist selected an object/activity in which the child appeared interested. Then the interventionist created an opportunity for expressive word use by verbally modeling a single word for the item/activity. For example, when a child showed interest in a toy, either by looking at or reaching for the item, the interventionist verbally prompted the child to name the object (e.g., "train"). The item was provided to the child contingent upon a word attempt or correct expressive label. This general procedure was repeated with a variety of child-preferred items and activities, several times per minute. In addition, systematic opportunities for unprompted responses were provided throughout the sessions by holding up an object and providing an opportunity for the child to independently label it.

\section{Intervention Condition-Individualized Orienting Cue}

During the intervention condition, all procedures were the same as in baseline, except the interventionist provided an individualized orienting cue at the start of each trial. Each orienting cue was presented immediately (less than $1 \mathrm{~s}$ ) prior to presenting a verbal model. To identify the orienting cue, a variety of stimuli were presented until the child: (a) oriented to the clinician; and (b) engaged in the activity related to the targeted stimulus. Identifying an orienting cue typically took less than $2 \mathrm{~h}$, and is described below.

For Zane, the first attempt to provide an orienting cue using modeled motor actions (e.g., making a circular motion with both hands, similar to a wheel going around and around, when providing the verbal model "car") did not result in any consistent orienting. Therefore, a second attempt to provide an orienting cue was initiated, using a "high-five" gesture. This stimulus consistently produced an orienting response from Zane, with him looking directly at the clinician and slapping her hand in a "high five" gesture, and, therefore, was provided as an orienting cue

Table 1 Sample child characteristics

\begin{tabular}{|c|c|c|c|c|c|}
\hline Child & Age & Diagnosis & VABS communication $^{\mathrm{a}}$ & Number of words on $\mathrm{CDI}^{\mathrm{b}}$ & Number of months in prior intervention \\
\hline Zane & $3: 0$ & Autistic disorder (DSM-IV-TR) & $0: 10$ & 0 & 8 \\
\hline Parker & $4: 1$ & Autism $(\mathrm{ADOS})^{\mathrm{c}}$ & $1: 2$ & 0 & 10 \\
\hline Alex & $4: 8$ & Autism (ADOS) & 1:0 & 1 & 13 \\
\hline
\end{tabular}

${ }^{a}$ Age equivalence on the Vineland adaptive behavior scales (Sparrow et al. 1984)

b MacArthur-Bates communicative development inventory: words \& sentences (CDI-WS; Fenson et al. 1993)

c Autism diagnostic observation schedule-generic (ADOS-G; Lord et al. 2000) 
immediately prior to presenting a verbal model during intervention.

For Parker, a combination of modeled motor actions and high-fives provided jointly with verbal models were the first attempts to produce an orienting response. However, as they did not produce an orienting response from Parker, a third attempt was made to provide an orienting cue by presenting novel stimuli such as hugs, kisses, tickles, and novel sounds. Such activities consistently produced orienting responses. Thus, novel actions were employed as orienting cues immediately prior to presenting verbal models during intervention.

For Alex, the first attempt at identifying an orienting cue, involving a modeled motor action presented simultaneously with a verbal model, effectively and consistently produced an orienting response. Therefore, an antecedent stimulus for motor imitation was provided immediately preceding the presentation of a verbal model throughout intervention.

\section{Interventionists}

All intervention providers had participated in practice with feedback sessions and had met fidelity of implementation as outlined in the instructional manual "Teaching First Words to Children with Autism and Communication Delays Using Pivotal Response Training" (Koegel et al. 2003). Intervention was provided by a graduate student for Parker and Alex during baseline and intervention. For Zane, all sessions were conducted in the context of parent education (where the parent served as the interventionist).

\section{Fidelity of Implementation}

Four sessions, selected randomly from both the baseline and intervention conditions, were scored on fidelity of implementation to assess whether the interventionists were implementing the intervention techniques correctly, as well as whether or not they presented orienting cues. Five minute blocks were segmented into trials (as described above in the baseline condition). Each trial was scored for correct use of the six standard components of the intervention as described in the manual, and for the presence or absence of an orienting cue, resulting in a percentage of trials where procedures were implemented correctly. Data on fidelity of implementation is presented in Table 2.

Table 2 Fidelity of implementation

\begin{tabular}{lll}
\hline & Baseline (\%) & Intervention (\%) \\
\hline General intervention fidelity & 98 (range 95-100) & 95 (range 90-100) \\
Presentation of orienting cue & 0 & 82 (range 80-85) \\
\hline
\end{tabular}

Dependent Measures

Data were collected for two dependent measures during baseline and intervention: (a) The percentage of correct verbalizations following a verbal model or independently produced by the child without a verbal prompt (i.e., when the object was merely held up in front of the child) and (b) Parent report on the number of words produced.

\section{Correct Verbalizations}

A correct verbalization was defined as an expressive verbal utterance that was phonetically similar to the presented verbal model (Yoder and Stone 2006). A correct response was recorded when it contained phonemes that corresponded to the verbal model or item/activity label. An incorrect response was recorded when all features of the child's response were phonetically dissimilar to the verbal model or item/activity label.

\section{Reliability of Correct Verbalizations}

Two observers, one of whom was naïve to the purpose of the study, independently recorded each of the child's verbal responses for $30 \%$ of the video probes from baseline and intervention sessions. Reliability was calculated on a trial by trial basis, using the formula agreements divided by agreements plus disagreements, multiplied by $100 \%$. The results yielded an average percent agreement of $80 \%$ (range $55-100 \%$, with disagreements occurring on only a few sessions due to the distance of the microphone from the child).

\section{Parent Report of Words Produced}

Following completion of the experimental condition, the MacArthur-Bates Communication Development Inventory (CDI): Words and Sentences form (CDI-WS; Fenson et al. 1993) was re-administered to determine the total number of words the children produced according to parent report.

\section{Reliability and Validity of the CDI-WS: Vocabulary Checklist}

The CDI-WS has high internal consistency for the 22 semantic categories in the vocabulary checklist of the form, yielding a Cronbach coefficient alpha value of .96. In addition, the short-term test-retest Pearson correlation is $.95(p<.01)$. The concurrent validity of this measure appears to be the best evidence for its reliability, yielding a correlation of .79 with measures of the child's observed vocabulary and structured tests such as the Expressive OneWord Picture Vocabulary Test (EOWPVT). 


\section{Results}

Figure 1 presents the children's responses during baseline and intervention. Weekly session probes are plotted on the abscissa with the percent of correct responses on the ordinate. As can be seen, during the baseline condition all of the children demonstrated very low levels of correct responding with no probes above $20 \%$. In contrast, immediate correct responding occurred during intervention, when the orienting cue was added, with correct phonemes occurring in the first session and whole words occurring shortly thereafter. Independent words (i.e., those
Fig. 1 Correct responding to verbal models presented by the interventionist during baseline and during the orienting cue intervention. Data points represent communication probes for the three children. The arrows indicate different milestones made by the three children during the communication probes.

Phoneme represents the first correct phoneme produced in response to a verbal model;

Word represents the first full word produced in response to a verbal model; and Independent refers to the first session where words were produced that were not immediately preceded by a verbal model

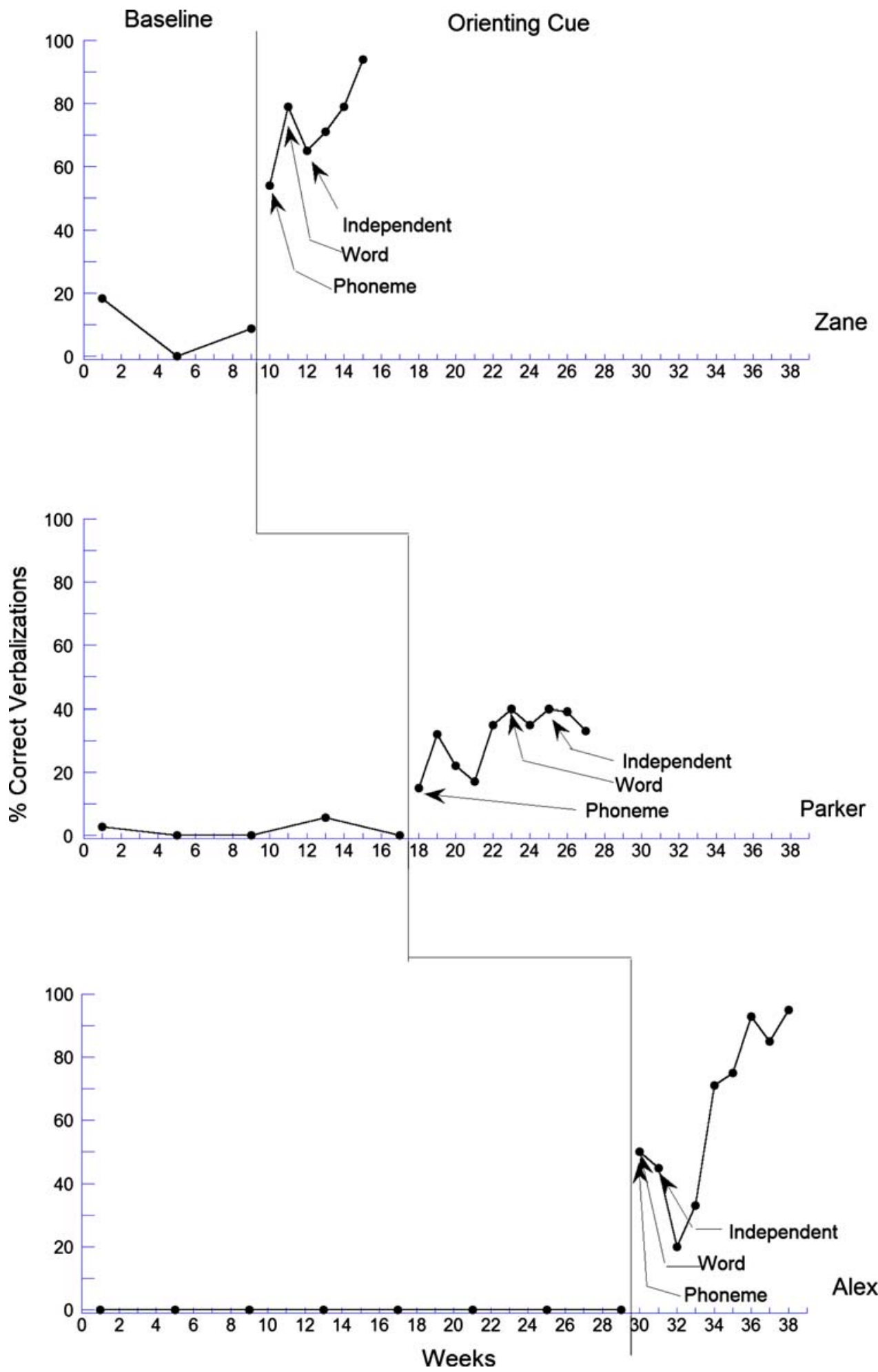


Table 3 Total number of words produced on the MacArthur-Bates CDI-WS before and after intervention and at a 6-month follow-up

\begin{tabular}{llrl}
\hline Child & Pre & Post & Follow-up \\
\hline Zane & 0 & 38 & 94 (2-3 word combinations) \\
Parker & 0 & 4 & 4 \\
Alex & 1 & 245 & 328 (Full sentences) \\
\hline
\end{tabular}

produced without a verbal prompt) began to occur shortly after that.

Table 3 shows the change in number of different words produced on the CDI following the orienting cue intervention. As can be seen, all children showed improvements in their word acquisition following the orienting cue intervention, with Alex and Zane showing the largest increases. While Zane and Alex displayed no words during the baseline condition, following intervention they exhibited 38 and 245 different words, respectively. In addition, both children continued to show improvement 6 months following intervention, with Zane's vocabulary increasing to 94 words and Alex's vocabulary increasing to 328 words. Zane frequently combined words, such as "go outside" and "(color) candy," and Alex used complete sentences (e.g., "I want to watch X," and "The bell is ringing"), with an MLU of 4.5 words. Although, Parker did not acquire as many words as the other two children, he consistently produced four during intervention ("no", "up", "go", and "open") and at follow up.

\section{Discussion}

This study assessed whether orienting cues could be identified and if they would facilitate word acquisition in nonverbal children with autism who were not responding to standard communication intervention. The results indicate that orienting cues were identified, and the cues did produce gains in verbal communication.

This study adds to the existing literature by demonstrating another technique that may be helpful with nonverbal children with autism (Lovaas 1977; Ross and Greer 2003; Tsiouri and Greer 2003; Wetherby and Prizant 2000). Additionally, it may suggest important areas for understanding autism. For example, responding to the relevant cue (in this instance the verbal model) during intervention may be of great importance in understanding children with autism (Lovaas et al. 1979). In addition, the notion of novelty, or how the stimulus properties of the language opportunity were changed (e.g. Carr et al. 1980), could be a fruitful area for future research. Moreover, since the orienting cue resulted in higher rates of reinforcement than the verbal model only, this may have produced behavioral momentum (Nevin et al. 1983) and likely increased the children's responsiveness to the verbal models. Finally, the extremely short duration (often less than $1 \mathrm{~s}$ ) between the orienting cue and the presentation of the verbal model may have been important (Koegel et al. 1980). These and other areas of research may be particularly important to pursue in future studies.

Acknowledgments The authors would like to acknowledge Research Grant MH28210 from the National Institute of Mental Health, and thank all of the undergraduate research assistants and families that assisted and participated in this research.

Open Access This article is distributed under the terms of the Creative Commons Attribution Noncommercial License which permits any noncommercial use, distribution, and reproduction in any medium, provided the original author(s) and source are credited.

\section{References}

American Psychiatric Association [APA]. (2000). Diagnostic and statistical manual of mental disorders (4th ed.). Washington, DC: Author.

Barlow, D. H., \& Hersen, M. (1973). Single-case experimental designs: Uses in applied clinical research. Archives of General Psychiatry, 29(3), 319-325.

Burack, J. A., Enns, J. T., \& Johannes, E. A. (1997). Attention and autism: Behavioral and electrophysiological evidence. In D. J. Cohen \& F. R. Volkmar (Eds.), Handbook of autism and pervasive developmental disorders (2nd ed., pp. 226-247). New York: Wiley.

Carr, E. G., Newsom, C. D., \& Binkoff, J. A. (1980). Escape as a factor in the aggressive behavior of two retarded children. Journal of Applied Behavior Analysis, 13(1), 101-117. doi: 10.1901/jaba.1980.13-101.

Charman, T., Taylor, E., Drew, A., Cockerill, H., Brown, J., \& Baird, G. (2005). Outcome at 7 years of children diagnosed with autism at age 2: Predictive validity of assessments conducted at 2 and 3 years of age and pattern of symptom change over time. Journal of Child Psychology and Psychiatry and Allied Disciplines, 46(5), 500-513. doi:10.1111/j.1469-7610.2004.00377.x.

Eaves, L. C., \& Ho, H. H. (2004). The very early identification of autism: Outcome to age 4 1/2-5. Journal of Autism and Developmental Disorders, 34(4), 367-378. doi:10.1023/ B:JADD.0000037414.33270.a8.

Fenson, L., Dale, P. S., Reznick, J. S., Thal, D., Bates, E., Hartung, J. P., et al. (1993). The MacArthur communicative development inventories : User's guide and technical manual. Baltimore: Paul H. Brookes Publishing Co.

Gillberg, C. (1991). Outcome in autism and autistic-like conditions. Journal of the American Academy of Child and Adolescent Psychiatry, 30(3), 375-382.

Goldstein, G., Johnson, C. R., \& Minshew, N. J. (2001). Attentional processes in autism. Journal of Autism and Developmental Disorders, 31(4), 433-440. doi:10.1023/A:1010620820786.

Howlin, P., Mahood, L., \& Rutter, M. (2000). Autism and developmental receptive language disorder-A follow-up comparison in early adult life: Social, behavioral, and psychiatric outcomes. Journal of Child Psychology and Psychiatry and Allied Disciplines, 41, 561-578. doi:10.1111/1469-7610.00643.

Koegel, L. K. (2000). Interventions to facilitate communication in autism. Journal of Autism and Developmental Disorders. Special Issue: Treatments for People with Autism and Other Pervasive 
Developmental Disorders: Research Perspectives, 30(5), 383-391.

Koegel, R. L., Dunlap, G., \& Dyer, K. (1980). Intertrial interval duration and learning in autistic children. Journal of Applied Behavior Analysis, 13(1), 91-99. doi:10.1901/jaba.1980.13-91.

Koegel, R. L., Dunlap, G., Richman, G. S., \& Dyer, K. (1981). The use of specific orienting cues for teaching discrimination tasks. Analysis and Intervention in Developmental Disabilities, 1(2), 187-198. doi:10.1016/0270-4684(81)90031-8.

Koegel, R. L., \& Koegel, L. K. (2006). Pivotal response treatments for autism: Communication, social, \& academic development. Baltimore, MD: Paul H Brookes Publishing.

Koegel, L. K., Koegel, R. L., Bruinsma, Y., Brookman, L., \& Fredeen, R. (2003). Teaching first words to children with autism and communication delays using pivotal response training. Santa Barbara: University of California.

Lord, C., Risi, S., Lambrecht, L., Cook, E. H., Jr, Leventhal, B. L., DiLavore, P. C., et al. (2000). The autism diagnostic observation schedule-generic: A standard measure of social and communication deficits associated with the spectrum of autism. Journal of Autism and Developmental Disorders, 30(3), 205-223. doi: 10.1023/A:1005592401947.

Lovaas, O. I. (1977). The autistic child: Language development through behavior modification. New York: Irvington.

Lovaas, O. I., Koegel, R. L., \& Schreibman, L. (1979). Stimulus overselectivity in autism: A review of research. Psychological Bulletin, 86(6), 1236-1254. doi:10.1037/0033-2909.86.6.1236.

McGee, G. G., Morrier, M. J., \& Daly, T. (1999). An incidental teaching approach to early intervention for toddlers with autism. The Journal of the Association for Persons with Severe Handicaps, 24(3), 133-146. doi:10.2511/rpsd.24.3.133.

Nevin, J. A., Mandell, C., \& Atak, J. R. (1983). The analysis of behavioral momentum. Journal of the Experimental Analysis of Behavior, 39(1), 49-59. doi:10.1901/jeab.1983.39-49.

Pelios, L. V., \& Lund, S. K. (2001). A selective overview of issues on classification, causation, and early intensive behavioral intervention for autism. Behavior Modification Special Issue Autism Part 1, 25(5), 678-697.

Ross, D. E., \& Greer, R. D. (2003). Generalized imitation and the mand: Inducing first instances of speech in young children with autism. Research in Developmental Disabilities, 24(1), 58-74. doi:10.1016/S0891-4222(02)00167-1.

Sherer, M. R., \& Schreibman, L. (2005). Individual behavioral profiles and predictors of treatment effectiveness for children with autism. Journal of Consulting and Clinical Psychology, 73(3), 525-538. doi:10.1037/0022-006X.73.3.525.

Sparrow, S., Balla, D., \& Cicchetti, D. (1984). Vineland adaptive behavior scales. Circle Pines, MN: American Guidance Service.

Tsiouri, I., \& Greer, R. D. (2003). Inducing vocal verbal behavior in children with severe language delays through rapid motor imitation responding. Journal of Behavioral Education, 12(3), 185-206. doi:10.1023/A:1025508311022.

Turner, L. M., Stone, W. L., Pozdol, S. L., \& Coonrod, E. E. (2006). Follow-up of children with autism spectrum disorders from age 2 to age 9. Autism, 10(3), 243-265. doi:10.1177/13623613060 63296.

Venter, A., Lord, C., \& Schopler, E. (1992). A follow-up study of high-functioning autistic children. Journal of Child Psychology and Psychiatry and Allied Disciplines, 33(3), 489-507. doi: 10.1111/j.1469-7610.1992.tb00887.x.

Wetherby, A., \& Prizant, B. M. (2000). Autism spectrum disorders: A transactional developmental perspective. Communication and language intervention series (Vol. 9). Baltimore, MD: Paul $\mathrm{H}$ Brookes Publishing.

Yoder, P., \& Stone, W. L. (2006). A randomized comparison of the effect of two prelinguistic communication interventions on the acquisition of spoken communication in preschoolers with ASD. Journal of Speech Language and Hearing Research: JSLHR, 49(4), 698-711. doi:10.1044/1092-4388(2006/051). 